\title{
Structure Topology Optimization Design of Brake Pad in Large Megawatt Wind Turbine Disc Brake
}

\author{
Zhihua Sha, Jian Yin, Shengfang Zhang*, Yu Liu \& Fujian Ma \\ School of Mechanical Engineering, Dalian Jiao Tong University, Dalian, 116028, China
}

\author{
*E-mail: zsf@djtu.edu.com
}

Keywords: wind turbine disc brake, megawatt level, brake pad, topology optimization

\begin{abstract}
The brake pad of disc brake, as an actuator while wind turbine braking, plays an important role in braking system. For seeking an optimum structure of brake pad, its mechanical model during braking process of large megawatt wind turbine in actual working circumstance is established in this paper. Accordingly, model of topology optimization is figured out. Based on the results of topological optimization, a new structure of brake pad is analyzed and a new design plan combined with actual working circumstance is suggested. Testing about new structure which has been done in this paper assures the accuracy.
\end{abstract}

\section{Introduction}

As a kind of renewable energy source, wind energy has no pollution with a large reserve. There're 2 trillion $\mathrm{kW}$ wind energy resources every year in the world, and only $1 \%$ of the ground wind can meet the energy demand for the whole world[1]. The main style of utilization of wind energy is wind power generation internationally[2]. With the development of wind power industry, the need for large megawatt wind turbine is going strong. The brake is an essential accessory for wind power generation, and its analysis and development plays an important role in wind energy technology. Modern brake moves forward to being light, efficient, reliable and discal[3]. During braking process, brake pad wears seriously under the combined action of heat and friction, which is asymmetrical and inevitable. Therefore, brake pad is needed to be high-friction-coefficient and low-wear-rate. So far, the research and manufacture of wind turbine brake pad is at the beginning stage[4]. To find new structure of brake pad made of copper base powder metallurgy materials to improve the utilization rate efficiently is very significant.

\section{Braking Principal of Wind Turbine and Performance Analysis of Disc Brake Pad}

Braking devices of large wind turbine aim to change the status from running to down. Braking devices can be divided into 2 categories: aerodynamic braking and mechanical braking. During the process of braking, they work together. Fig.1 shows the working principal of braking system. Top Management System gets signal from monitoring of Power Network, Wind, Halt Instruction or Wind Turbine itself. Then wind turbine will be stopped by Mechanical and Aerodynamic Braking.

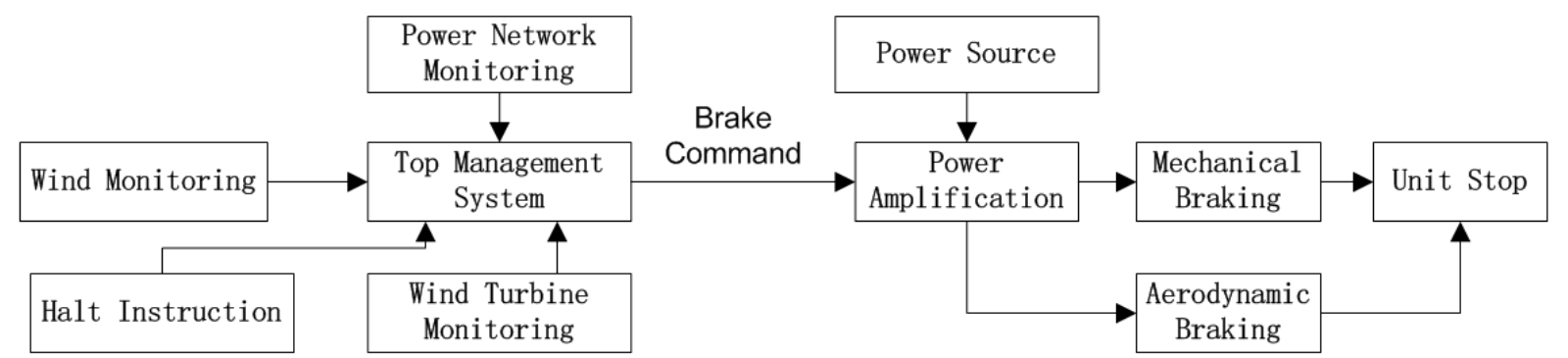

Fig.1: Principles of braking systems

Mechanical device works through friction between rotary and non-rotary components to prevent rotation and the tendency[5]. Fig.2 shows the actual structure of wind turbine brake. Brake caliper is fixed on high-speed side of gear case. While wind turbine working normally, pressure will make a 
small and stable gap between disc and caliper; while wind turbine needs braking, force provided by compression spring will make pad and disc plying-up. After braking, the brake caliper will fix itself to compensate the abrasion during braking to make sure the stable gap mentioned before. When it gets the limit abrasion of the pad, braking system will alarm automatically to change brake pad.

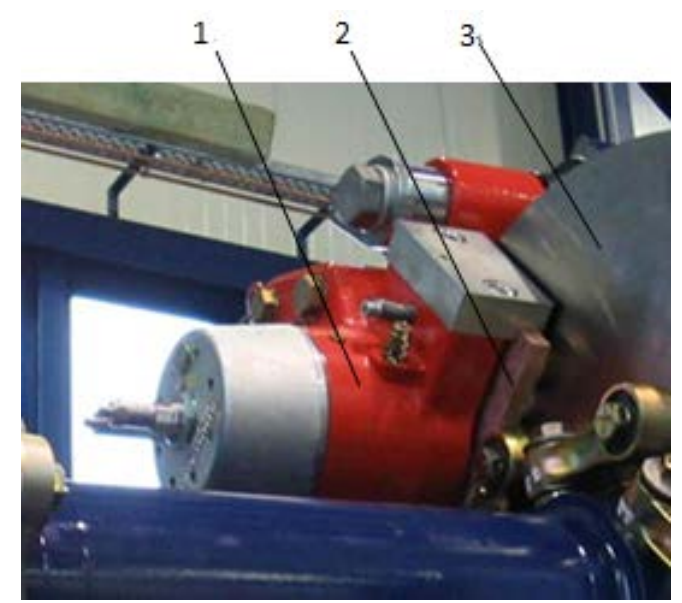

1 brake caliper 2 brake pad 3 brake disc

Fig.2: Structure of wind turbines

\section{D Model of Wind Turbine Brake Pad}

The size of brake pad is got from mechanical braking device of a certain type of 2 MW wind turbine[6], which is shown in Table 1.

Table 1: Dimensions of brake pad

\begin{tabular}{lllll}
\hline Length $/ \mathrm{mm}$ & Width $/ \mathrm{mm}$ & Thickness $/ \mathrm{mm}$ & $\begin{array}{l}\text { Width of two } \\
\text { sides } \\
\text { grooves } / \mathrm{mm}\end{array}$ & $\begin{array}{l}\text { Depth of two } \\
\text { sides } \\
\text { grooves } / \mathrm{mm} \\
270\end{array} \mathrm{lng}^{2}$ \\
\hline
\end{tabular}

Such single section stretched component can be meshed into 2D gridding, then mapping into 3D. Also, the density of gridding will influence the result seriously[7-8]. Before static analysis of brake pad, the working condition should be described. First of all, two sides grooves of the pad can be seen as guide rails, which guides the pad move up and down along axis $\mathrm{Z}$ and makes sure the joint and separation of brake pad and disc, which means the 6 surfaces of the two sides grooves (perpendicular to Plan XOY, 3 surfaces per side) should be restrained by dof 1 and dof 2(the degrees of freedom of moving in X and Y[9]). Secondly, bottom surface of brake pad and top surface of brake disc fix together tightly while braking, which means that dof 3(the degree of freedom of moving in Z) of all nodes on bottom surface of brake pad should be restrained.

While braking, brake caliper and other clamping devices would affect a force along the negative axis $\mathrm{Z}$ in a circle area on top surface of brake pad. On bottom surface of brake pad, because of the contact between brake pad and disc, there's a friction whose direction is opposite to the linear velocity. To simplify the calculation, we put forward some assumptions: firstly, the turning radius of brake disc is infinitely great, then directions of friction effects on every nodes is the same (parallel to axis X); secondly, the friction coefficient never changes as other conditions change. The finite element model after binding and forcing is showed in Fig.3. Attribute parameters of copper base powder metallurgy materials are tabled in Table 2. 


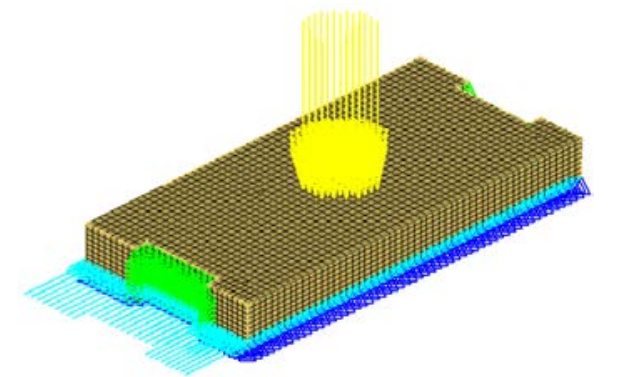

Fig.3: Finite element model after binding and forcing Table 2 Material parameters of copper-based powder metallurgy

\begin{tabular}{lcccc}
\hline $\begin{array}{l}\text { Elasticity } \\
\text { Modulus }\end{array}$ & Density & $\begin{array}{l}\text { Poisson's } \\
\text { Ratio }\end{array}$ & $\begin{array}{l}\text { Coefficient } \\
\text { Friction }\end{array}$ & of Sliding \\
\hline $5.2 \mathrm{GPa}$ & $5250 \mathrm{~kg} / \mathrm{m} 3$ & 0.3 & 0.35 & \\
\hline
\end{tabular}

\section{Static Analysis and Topology Optimization}

Contours of displacement (Fig.4(a)) and stress (Fig.4(b)) are shown as following.

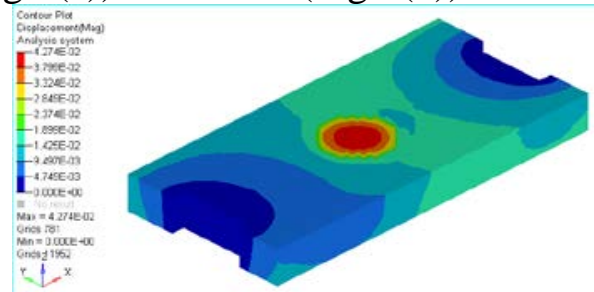

(a) displacement

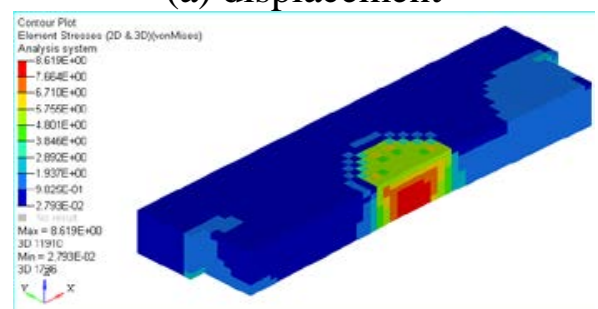

(b) stress (half model)

Fig.4: Displacement and stress contour of static analysis

In Fig.4(a), nodes with maximum displacement appear in the circle area in which brake pad and caliper contact, viz. the plan of action of the positive force. The brake pad is cut in half in Fig.4(b) to show the maximum stress place. The maximum stress appears on bottom surface of brake pad corresponding to the circle on top surface. Nodes here stress resultant force of positive force and friction. Results of displacement and stress provide restrains for topology optimization of the brake pad. The result of topology optimization should meet the need of maximum rigidity, viz. the displacement of the point in the circle on top surface should be not less than $0.05 \mathrm{~mm}$.

Variable Density Method takes the density of every element as design variable, changes structural topology design to optimal distribution of material, uses optimality criteria or mathematical programming approach to solve optimal distribution of material. The design variations of static stiffness topology optimization is the density of every element, the objective function is the best power transmission line to meet the need of maximum rigidity and the constraint condition is that optimization should be solved under working condition. The mathematic model can be described as:

$$
\begin{gathered}
\text { Minimize }: f(X)=f\left(x_{1}, x_{2}, \cdots, x_{n}\right) \\
\text { Subjectto }: g_{j}(X) \leq 0(j=1,2, \cdots, m) \\
\qquad h_{k}(X) \leq 0\left(k=1,2, \cdots, m_{h}\right)
\end{gathered}
$$

where, $X=\left(x_{1}, x_{2}, \cdots x_{n}\right)$ is the design variations; Eq.(1) is the design objective; Eq.(2) and (3) 
are the responses which should be restrained. The new structure of topology model is shown in Fig.5.

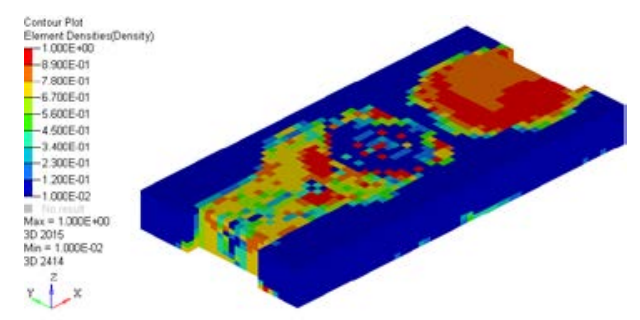

(a) density interval $[0,1]$

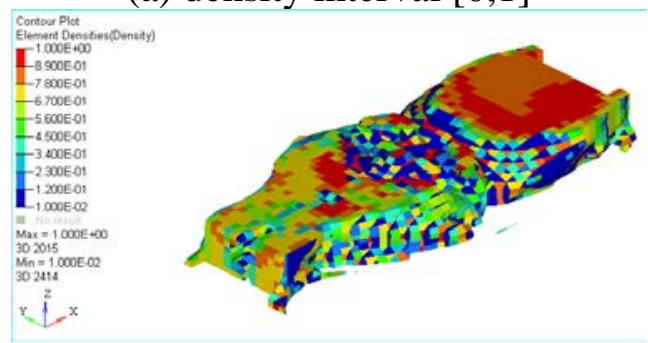

(b) density interval [0.4,1]

Fig.5: Topology optimization model of brake pad

In Fig.5, density of element changes from 0 to 1. Fig.5(a) shows all elements, and Fig.5(b) shows the elements whose density is not less than 0.4. To describe conveniently, the direction of friction is along axis $\mathrm{X}$ in Fig.5, the positive is exit and the negative is entrance. Conclusions are showed in following parts: (1) Along the direction form entrance to exit in Fig.5(b), density of elements gets generally closed to 1 . This is because that according to composition of forces theorem, the direction of resultant force is the exit. By contrast, brake pad and brake disc contact even closer, which causes serious abrasion during braking. So the thickness of the exit should be larger than that of the entrance is necessary, which can improve the stability caused by uneven wear.(2) In Fig.5(a), density of elements in width is close to 0 , which states no material. This is because the two sides in width of brake pad have a degree of buckling deformation. Fig.4(a) explains this phenomenon, in which color of two sides in width is not blue totally, which proves the existence of buckling deformation. Buckling deformation will decrease the contact area between brake pad and brake disc. Abrasion will be much more serious than other contact area, so material should be deleted to make wear even.(3) There is a circular depression on top surface in Fig.5(b). Maximum contact stress created by the brake pad and brake disc locates on subsurface, not the surface. There is a very small distance between the surface and the subsurface. That's why topology optimization result deletes material there. But considering the processing technic, this remove can be ignored.

Fig.6 shows new structure. Static analysis with same working conditions is done to verify reasonability of the new structure. Contour of density of the elements is showed in Fig.7. There is a great improvement material reservation than before.

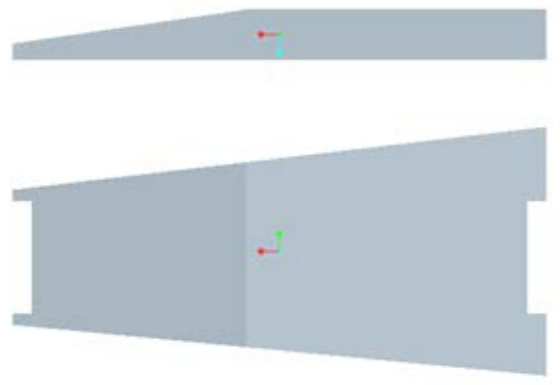

Fig.6: Topology optimization model of brake pad after simplification 

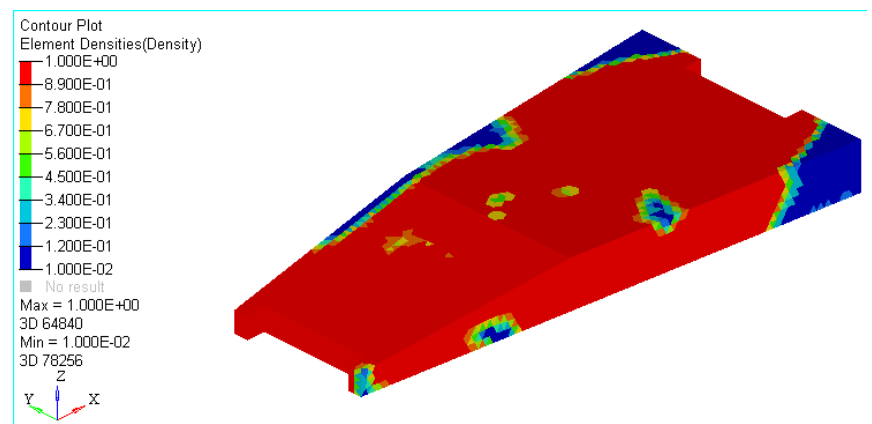

Fig.7: Density contour of the simplified model with constraints and forces

\section{Conclusions}

Almost 95\% of the volume should be maintained. Compare with primary structure, the volume decreased about 28.6\%. Meanwhile, using ratio of copper-base powder metallurgy material is promoted. New method of designing brake pad in megawatt wind turbine disc brake is suggested in this paper. Structure of brake pad figured in this method meets the rigidity as before. Results show that the new structure has higher stability.

\section{Acknowledgements}

The research work was supported by National Natural Science Foundation of China under Grant No. 51475066 and Dalian Municipal Science and Technology Foundation under Grant No. 2013J21DW011.

\section{References}

[1] BAO Er. Current situation of development of wind power generation technology[J]. Renewable Energy, 2004.4:53-55.

[2] ZHAO Jianzhu, MAO Enrong, DONG Sheng, etc. The application of wind power and sustainable development[J]. Journal of Agricultural Mechanization Research, 2004.11:40-42.

[3] ZHAO Xinghua. Design and vibration stabilization analysis of the caliper construction in wind-driven generator[D]. Dalian: Dalian University of Technology, 2009.12.

[4] YU Xiao, GUO Zhimeng, HAO Junjie, etc. Preparation and properties of copper-based powder metallurgy brake pad for wind turbine[J]. Materials Science and Engineering of Powder Metallurgy, 2014.19(1):66-70.

[5] YAO Xingjia, SONG Jun. Theory and application of wind turbine generator system(2nd edition)[M]. Beijing: China Machine Press, 2011.

[6] WANG Yudong, JIN Lei, HONG Qingquan, etc. HyperMesh \& HyperView application techniques and advanced examples[M]. Beijing: China Machine Press, 2013.

[7] WU Zhongbo, LI Shu. Topology optimization in static and dynamic states based on OptiStruct[J]. Aeronautical Computing Technique, 2006.36(6):9-12.

[8] LIU Yu, ZHANG Shengfang, SONG Xueping, etc. Topological optimization design on frame structure of power platform trailers[J]. Chinese Journal of Construction Machinery, 2014.12(1):34-37.

[9] HONG Qingquan, ZHAO Kang, ZHANG Pan, etc. OptiStruct \& HyperStudy theoretical basement and engineering application[M]. Beijing: China Machine Press, 2012. 